\title{
Demonstration of Thyrotropin-Releasing Hormone Immunoreactivity in Neurons of the Mouse Spinal Dorsal Horn
}

\author{
J. A. Coffield, ${ }^{\star}$ V. Miletic, ${ }^{\star}$ E. Zimmermann, $\dagger$ M. J. Hoffert, $\dagger$ and B. R. Brooks $\ddagger$ \\ *Department of Comparative Biosciences, School of Veterinary Medicine, University of Wisconsin, \\ Madison, Wisconsin 53706, †Neurology Department, University of Wisconsin Medical School, Madison, Wisconsin \\ 53792, and \$Neurology Department, University of Wisconsin Medical School, and Neurology Service, \\ William S. Middleton Memorial Veterans Hospital, Madison, Wisconsin 53792
}

\begin{abstract}
Thyrotropin-releasing hormone-like immunoreactivity was demonstrated in neurons within the superficial laminae (I, II, III) of the mouse spinal dorsal horn by light-microscopic peroxidase immunocytochemistry. The immunoreactivity was distributed in a narrow dorsoventral band that enclosed the substantia gelatinosa (lamina II), with a higher concentration along the lamina II/III border. At present, the functional significance of these neurons is unknown. Their existence within the substantia gelatinosa suggests a role in sensory information processing.
\end{abstract}

Thyrotropin-releasing hormone (TRH) is a neuropeptide originally isolated from bovine and porcine hypothalamic tissue. Its characterization as a hypothalamic releasing hormone is well documented (Vale and Rivier, 1975). Within the last decade, however, numerous studies have revealed that two-thirds of the total CNS content of TRH is contained within extrahypothalamic tissue (Brownstein et al., 1974; Jackson and Reichlin, 1974; Oliver et al., 1974; Winokur and Utiger, 1974). Indirect immunofluorescence and peroxidase-antiperoxidase (PAP) immunocytochemical techniques have been used to localize TRHlike immunoreactivity (TRH-LI) in neuronal cell bodies, processes, and vesicle-containing varicosities (Hökfelt et al., 1975; Johansson and Hökfelt, 1980; Johansson et al., 1980). These immunoreactive profiles have been seen in axoaxonic, axodendritic, and axosomatic synaptic specializations (Shioda and Nakai, 1983), suggesting a role for TRH in synaptic transmission in addition to its established role as a hypothalamic releasing hormone. Iontophoretic application of TRH onto rodent motoneurons indicates that the peptide may more accurately be described as a modulator since it does not evoke neuronal activity per se, but rather potentiates glutamate excitation (White, 1983).

Until recently, reports on the distribution of TRH-LI within the spinal cord have described its presence as limited to varicose fibers within the ventral horn in close association with motoneurons (Hökfelt et al., 1975; Johansson and Hökfelt, 1980; Johansson et al., 1981; Kardon et al., 1977). These fibers are

\footnotetext{
Received June 24, 1985; accepted Aug. 27, 1985.

We wish to thank M. Behan and R. Berlow for their critical review of the manuscript. Supported in part by National Institutes of Health Grant NS 21278 to V.M. and a grant from the Amyotrophic Lateral Sclerosis Society of America to B.R.B.

Correspondence should be addressed to Julie Ann Coffield, Department of Comparative Biosciences, School of Veterinary Medicine, University of Wisconsin, 2015 Linden Drive West, Madison, WI 53706.

Copyright (C) 1986 Society for Neuroscience $0270-6474 / 86 / 041194-04 \$ 02.00 / 0$
}

thought to originate in certain brain stem nuclei and to contain 5-HT and/or substance $P$ in addition to TRH (Johansson et al., 1981). Recent autoradiographic studies, however, have revealed that the highest concentration of TRH receptors is within the dorsal, rather than the ventral, horn (Manaker et al., 1985; Mantyh and Hunt, 1985; Sharif and Burt, 1983).

While little is known about a functional role for TRH in the dorsal horn, several other neuropeptides have been localized to this region, and ongoing investigations of their functional significance focus on their involvement in the synaptic transmission of sensory, especially nociceptive, input and its modulation (Hunt et al., 1981). TRH demonstrates no direct analgesic effect (Martin et al., 1977; Nemeroff et al., 1979); however, it has been shown to antagonize neurotensin-induced analgesia (Osbahr et al., 1981). The effects of TRH on opiate analgesia are inconclusive. Intracerebroventricular administration of TRH is reported to potentiate some forms of stress-induced analgesia, i.e., footshock analgesia (opiate), and swim analgesia (Butler and Bodnar, 1984; Butler et al., 1984). Intrathecal administration of TRH yiclds differential effects on morphine analgesia, i.e., inhibiting at high $(2.5 \mu \mathrm{g})$ and low $(0.25 \mathrm{ng})$ doses, while potentiating at middle doses (2.5 ng) (Watkins et al., 1984).

In order to study the role of TRH in the dorsal horn we have employed the PAP immunocytochemical technique to examine the distribution of TRH within the spinal cord. Here, we provide evidence for the existence of TRH-LI within neurons in the mouse superficial dorsal horn.

\section{Materials and Methods}

Immunocytochemical experiments were conducted on 21 mouse spinal cords (NIH:N strain). Under sodium pentobarbital anesthesia, the mice were heparinized and perfused transcardially with physiological saline $\left(25^{\circ} \mathrm{C}\right)$ followed by $4 \%$ paraformaldehyde containing $0.05-0.2 \%$ glutaraldehyde in $0.1 \mathrm{~m}$ phosphate buffer $\left(\mathrm{pH} 7.4,4^{\circ} \mathrm{C}\right)$. The spinal cord and brain stem were removed intact and stored in fresh fixative for an additional $2-4 \mathrm{hr}$ at $4^{\circ} \mathrm{C}$. Fifty micrometer transverse or parasagittal sections of the cervical, thoracic, lumbar, and sacral spinal segments were cut with a vibratome. The sections were rinsed in $0.1 \mathrm{M}$ PBS. To identify areas of TRH localization we employed the PAP immunocytochemical technique (Ruda et al., 1982) using a rabbit antibody raised against TRH conjugated to bovine serum albumin (TRH-BSA, Institut Pasteur). Free-floating sections were incubated in TRH antisera dilutions of 1:250-1:600 at $4^{\circ} \mathrm{C}$ for $48-72 \mathrm{hr}$, with gentle agitation. The sections were subsequently incubated in goat anti-rabbit (GAR) IgG serum (1:50) followed by incubation in PAP complex (1:80). The primary antibody (anti-TRH), link antibody (GAR), and PAP complex were diluted in $1 \%$ normal goat serum containing $0.75 \%$ Triton $X-100$ to ensure maximum antibody penetration throughout the $50 \mu \mathrm{m}$ tissue section thickness (Ruda et al., 1982). All three antibody incubations were preceded by PBS washes, and a 30 min blocking wash in $3 \%$ normal 


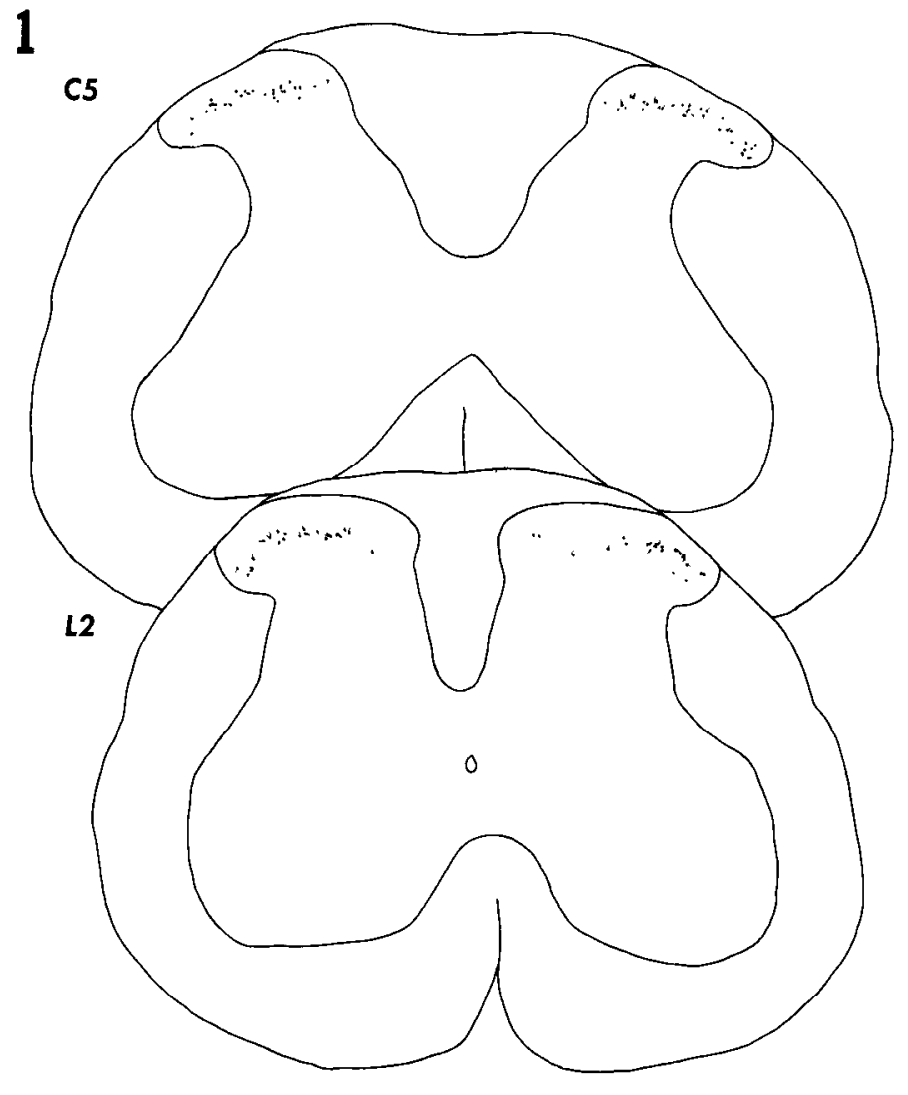

Figure 1. Schematic representation demonstrating approximate size, shape, and distribution of the mouse dorsal horn neurons stained for TRH-LI. Their shape is oval. They are located within the superficial laminae (40-200 $\mu \mathrm{m}$ from the dorsal white-gray matter border) and are concentrated along the laminae II/III border $(100-180 \mu \mathrm{m})$. To better illustrate the distinctive banding of these cells, each drawing represents a composite of three semiserial $50 \mu \mathrm{m}$ transverse sections taken from segments C 5 and L2 of the cervical and lumbar cord, respectively. Scale bar, $100 \mu \mathrm{m}$.

goat serum to minimize nonspecific background staining. After the PAP incubation, the sections were washed in PBS and incubated for 7-10 $\min$ in $0.05 \%$ diaminobenzidine $\mathrm{HCl}$ in $0.1 \mathrm{M}$ PBS reacted with $0.01 \%$ hydrogen peroxide to obtain the distinctive reddish-brown label distinguishable with the light microscope. The sections were mounted on gelatin-coated slides, dehydrated in ethanol, cleared in xylene, and coverslipped using Permount. Sections were examined for TRH-LI under the light microscope. Immunoreactive cell bodies were drawn with a $20 \times$ objective using the camera lucida technique.

In initial specificity control experiments, $50 \mu \mathrm{m}$ transverse sections of the hypothalamus (containing the median eminence) were similarly processed for TRH-LI using this antibody. These areas are known to be positive for TRH localization. In addition, antibody specificity and cross-reactivity were determined by preabsorption of the TRH antisera with $100 \mathrm{mg}$ TRH or with $100 \mathrm{mg}$ of the following putative neurotransmitters: cholecystokinin (CCK), leucine-enkephalin (L-ENK), neurotensin (NT), 5-hydroxytryptamine (5-HT), somatostatin (SS), substance $\mathrm{P}(\mathrm{SP})$, and vasoactive intestinal polypeptide (VIP). Radioimmunoassay studies by the Institute Pasteur show this antibody to be highly specific for TRH, with a cross-reactivity of less than $0.01 \%$ to TRH analogs TRH-OH, L-Pyroglu-L-His-OH, and L-Pyroglu-L-His-NH2, and to luteinizing hormone-releasing hormone. Using this antiserum, localization of TRH-LI within hypothalamic regions known to contain TRH and in the ventral horn is consistent with previous findings (not shown). The TRH-LI in the spinal dorsal horn is almost completely blocked by preabsorption with TRH, but is neither blocked nor reduced by preabsorption with other putative CNS transmitters (CCK, NT, 5-HT, SS, SP, VIP).
Table 1. Location, morphology, numbers, and sizes of neurons demonstrating TRH-LI in the mouse spinal dorsal horn

\begin{tabular}{lll} 
& Lamina location (\%) & \\
\cline { 2 - 3 } Cells examined $(n)$ & IIb & Ila and III \\
\hline 659 & 70 & 30
\end{tabular}

Somata shape and orientation (\%)

\begin{tabular}{lll}
\hline $\begin{array}{l}\text { Fusiform; } \\
\text { rostro- } \\
\text { caudal } \\
\text { processes }\end{array}$ & $\begin{array}{l}\text { Round; } \\
\text { dorso- } \\
\text { ventral } \\
\text { processes }\end{array}$ & $\begin{array}{l}\text { Round/ } \\
\text { oval; no } \\
\text { visible } \\
\text { processes }\end{array}$ \\
\hline 81 & 10 & 9 \\
0 & 9 & 91
\end{tabular}

Transverse plane, 396

Mean number and size of cells $s^{a}$

\begin{tabular}{lcl} 
& \multicolumn{2}{c}{ Mean number and size of cell $\mathrm{s}^{a}$} \\
\cline { 2 - 3 } & Number & $\begin{array}{l}\text { Soma size } \\
(\mu \mathrm{m})\end{array}$ \\
\hline Cervical level, 171 & $10.1( \pm 4.5)$ & $8.1( \pm 1.6)$ \\
Lumbar level, 196 & $9.1( \pm 3.8)$ & $8.7( \pm 1.2)$
\end{tabular}

${ }^{a}$ Cell numbers and somata sizes are based on counts and measurements per single dorsal horn taken from $50 \mu \mathrm{m}$ transverse sections.

\section{Results}

Light-microscopic examination of the mouse spinal cord reveals TRH-LI in neurons of the dorsal horn at all levels of the spinal cord. Direct measurements place these neurons within the superficial laminae, $40-200 \mu \mathrm{m}$ from the dorsal gray-white matter border. Superimposition of camera lucida drawings taken from three to four serial transverse sections illustrates that the immunoreactive neurons form a dorsoventral band that encompasses the substantia gelatinosa (lamina II) with a selective concentration along the lamina II/III border, approximately 100 $180 \mu \mathrm{m}$ from the dorsal white-gray matter border (Fig. 1). Approximately $70 \%$ of these neurons can be found in the ventral two-thirds of lamina II, lamina IIb. The remaining $30 \%$ are found in lamina IIa and dorsal lamina III. The immunoreactivity is confined to the cell body and proximal $30 \mu \mathrm{m}$ of their primary dendrites. In the parasagittal plane, $81 \%$ of the total immunoreactive neurons ( $n=263$ ) have oval or fusiform cell bodies with primary processes arising from their rostrocaudal poles (Fig. 2). They exist in clusters with no apparent periodicity. A much smaller percentage (10\%) have more rounded or triangularly shaped cell bodies with primary processes projecting dorsoventrally (not shown). The remaining $9 \%$ do not demonstrate immunoreactive processes. In the transverse plane, all of the cell bodies tend to be more rounded. Approximately $9 \%$ of these neurons $(n=396)$ demonstrate dorsoventrally projecting proximal dendrites. These data, and the numbers and sizes of immunoreactive TRH neurons in lumbar and cervical sections of the dorsal horn, are summarized in Table 1.

\section{Discussion}

Using PAP immunocytochemistry we have localized TRH-LI to neuronal cell bodies of the superficial dorsal horn (laminae I-III). Our immunocytochemical technique enables us to visualize the immunoreactive cell body and the most proximal $30 \mu \mathrm{m}$ of the primary dendrites, but not the full extent of their dendritic arbors. Consequently, unequivocal identification of morphological cell type is not possible. Nevertheless, our data suggest that the TRH-LI is contained in at least two morphologically distinct interneuronal cell types. We base this morphological 


\section{$2 a$}

Figure 2. $a$, High-magnification photomicrograph of a TRH-immunoreactive neuron in a $50 \mu \mathrm{m}$ parasagittal cervical section of the mouse spinal dorsal horn. The oval cell has proximal processes (arrows) arising from each pole of the cell body extending in the rostrocaudal direction (rostral at left). Scale bar, $10 \mu \mathrm{m}$. $b$, Low-magnification photomicrograph of same cervical section shown in $a$. The asterisk indicates the neuron shown under high magnification in $a$. The tight dorsoventral banding of the neurons is clearly evident and is demarcated by the arrowheads. Dotted line at left indicates laminar borders. Scale bar, $100 \mu \mathrm{m}$.

\section{Dorsal}
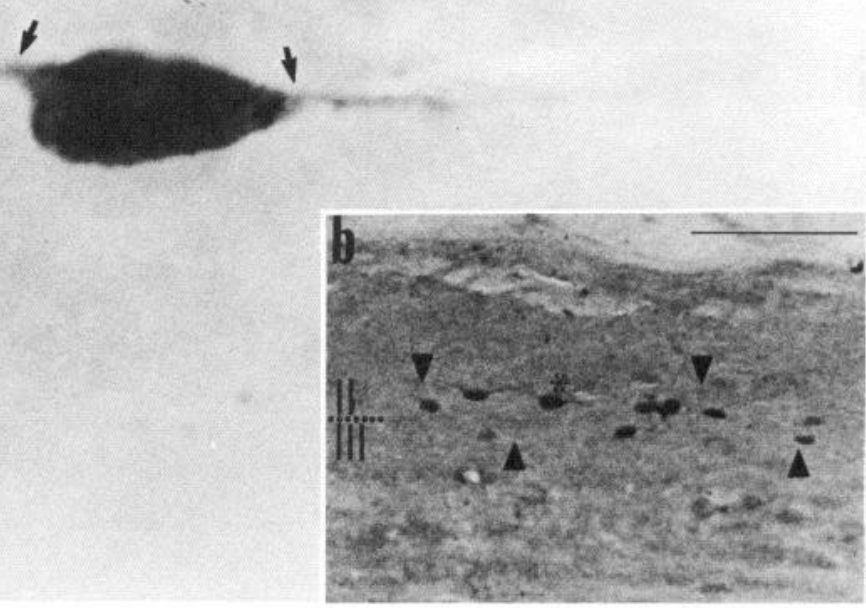

distinction on the location of the neuron within the dorsal horn, the shape of the cell body, and the orientation of its primary dendrites. The majority of the TRH-immunoreactive neurons are located within lamina IIb. Eighty-one percent of these neurons exist in clusters and have oval or fusiform cell bodies with rostrocaudally projecting primary processes. The predominant cell type encountered in both anatomical and physiological studies of lamina IIb is the islet cell (Bennett et al., 1980; Gobel, 1975, 1978; Light et al., 1979; Miletic et al., 1984). Lamina IIb islet cells have oval or fusiform cell bodies with primary dendrites projecting from their rostrocaudal poles, and they typically exist in clusters. This suggests that most of the TRH-LI seen in the ventral substantia gelatinosa is contained in IIb islet cells. It is noteworthy that previous studies have reported the existence of several other neurons containing peptide-like substances within the substantia gelatinosa. These include avian pancreatic polypeptide, L-ENK, NT, SS, and SP (Hunt et al., 1981). Some of these neurons were also thought to be IIb islet cells (Bennett et al., 1982; Seybold and Elde, 1982). The possibility that TRH and/or any of these other peptides coexist within the same neuron remains to be established.

Approximately $10 \%$ of the TRH-immunoreactive neurons have a more rounded or triangularly shaped cell body with proximal processes projecting dorsoventrally. The majority of these neurons are found deep in lamina IIb, near the lamina II/ III border. These neurons bear a morphological similarity to the spiny cell (Gobel, 1975, 1978) in location, cell body shape, and orientation of their primary dendrites. The spiny cell has a polygonal cell body and dorsoventrally projecting primary dendrites, and is found between islet cell clusters in the substantia gelatinosa, frequently in lamina IIb near the lamina II/ III border.

A smaller percentage of TRH-immunoreactive neurons is found in lamina IIa, and in the outermost region of lamina III. These neurons may represent any of the other interneuronal cell types described in this area, i.e., stalked, IIa islet, arboreal, or IIa/IIb border cells (Gobel, 1975, 1978).

The presence of TRH-immunoreactive neurons on both sides of the lamina II/III border indicates a possible role for TRH as a neurotransmitter or neuromodulator in the processing of cutaneous sensory information. This region is the main termination site of primary afferent fibers signaling innocuous, rather than noxious, information (Dubner and Bennett, 1983). Physiological studies of lamina IIb islet cells indicate that they are exclusively low-threshold mechanoreceptive neurons, i.e., maximally activated by innocuous cutaneous stimulation (Bennett et al., 1980; Light et al., 1979; Miletic et al., 1984).

We present immunocytochemical evidence for the existence of TRH in dorsal horn neurons of the mouse spinal cord. This finding is in agreement with recent studies establishing that the highest concentration of spinal cord TRH receptors is in the substantia gelatinosa (Manaker et al., 1985; Mantyh and Hunt, 1985; Sharif and Burt, 1983). Additionally, TRH-immunoreactive neurons have also been seen in the rat superficial dorsal horn (Harkness and Brownfield, personal communication).The functional significance of TRH-containing neurons in the rodent dorsal horn is presently unknown. Their exclusive existence within the superficial laminae and their high density within the substantia gelatinosa suggest a role in the modulation of sensory input. Additional studies, however, are needed to establish the precise role of TRH in the neural circuitry of the dorsal horn.

\section{References}

Bennett, G. J., M. Abdelmoumene, H. Hayashi, and R. Dubner (1980) Physiology and morphology of substantia gelatinosa neurons intracellularly stained with horseradish peroxidase. J. Comp. Neurol. 194: 809-827.

Bennett, G. J., M. A. Ruda, S. Gobel, and R. Dubner (1982) Enkephalin immunoreactive stalked cells and lamina IIb islet cells in cat substantia gelatinosa. Brain Res. 240: 162-166.

Brownstein, M. J., M. Palkovits, J. M. Saavedra, R. M. Bassiri, and R. D. Utiger (1974) Thyrotropin-releasing hormone in specific nuclei of rat brain. Science 185: 267-269.

Butler, P. D., and R. J. Bodnar (1984) Potentiation of foot shock analgesia by thyrotropin releasing hormone. Peptides 5: 635-639.

Butler, P. D., E. Sperber, P. Mann, and R. J. Bodnar (1984) Potentiation of analgesic responses following central but not peripheral 
administration of thyrotropin releasing hormone. Soc. Neurosci. Abstr. 10: 176.

Dubner, R., and G. J. Bennett (1983) Spinal and trigeminal mechanisms of nociception. Annu. Rev. Neurosci. 6: 381-418.

Gobel, S. (1975) Golgi studies of the substantia gelatinosa neurons in the spinal trigeminal nucleus. J. Comp. Neurol. 162: 397-415.

Gobel, S. (1978) Golgi studies of the neurons in layer II of the dorsal horn of the medulla (trigeminal nucleus caudalis). J. Comp. Neurol. 180: 395-414.

Hökfelt, T., K. Fuxe, O. Johansson, S. L. Jeffcoate, and N. White (1975) Thyrotropin releasing hormone (TRH)-containing nerve terminals in certain brain stem nuclei and in the spinal cord. Neurosci. Lett. I: 133-139.

Hunt, S. P., J. S. Kelly, P. C. Emson, J. R. Kimmell, R. Miller, and J.-Y. Wu (1981) An immunohistochemical study of neuronal populations containing neuropeptides or GABA within the superficial layers of the rat dorsal horn. Neuroscience 6: 1883-1898.

Jackson, I.M.D., and S. Reichlin (1974) Thyrotropin-releasing hormone (TRH): Distribution in hypothalamic and extrahypothalamic brain tissues of mammalian and submammalian chordates. Endocrinology 95: 854-862.

Johansson, O., and T. Hökfelt (1980) Thyrotropin-releasing hormone, somatostatin and enkephalin: Distribution using immunohistochemical techniques. J. Histochem. Cytochem. 28: 364-366.

Johansson, O., T. Hökfelt, S. L. Jeffcoate, N. White, and L. A. Sternberger (1980) Ultrastructural localization of TRH-like immunoreactivity. Exp. Brain Res. 38: 1-10.

Johansson, O., T. Hökfelt, B. Pernow, S. L. Jeffcoate, N. White, H. W. M. Steinbusch, A. A. J. Verhofstad, P. C. Emson, and E. Spindel (1981) Immunohistochemical support for three putative transmitters in one neuron: Coexistence of 5-hydroxytryptamine, substance P- and thyrotropin releasing hormone-like immunoreactivity in medullary neurons projecting to the spinal cord. Neuroscience 6: 1857-1881.

Kardon, F. C., A. Winokur, and R. D. Utiger (1977) Thyrotropinreleasing hormone (TRH) in rat spinal cord. Brain Res. 12: 578-581.

Light, A. R., D. L. Trevino, and E. R. Perl (1979) Morphological features of functionally defined neurons in the marginal zone and substantia gelatinosa of the spinal dorsal horn. J. Comp. Neurol. 186: 151-172.

Manaker, S., A. Winokur, W. H. Rostene, and T. C. Rainbow (1985) Autoradiographic localization of thyrotropin-releasing hormone receptors in the rat central nervous system. J. Neurosci. 5: 167-174.

Mantyh, P. W., and S. P. Hunt (1985) Thyrotropin-releasing hormone receptors. Localization by light microscopic autoradiography in rat brain using $\left[{ }^{3} \mathrm{H}\right]$ [3-Me-His $]$ TRH as the radioligand. J. Neurosci. 5: $551-561$.
Martin, B. R., W. L. Dewey, T. Chau-Pham, and A. J. Prange, Jr. (1977) Interactions of thyrotropin releasing hormone and morphine sulfate. Life Sci. 20: 715-722.

Miletic, V., M. J. Hoffert, M. A. Ruda, R. Dubner, and Y. Shigenaga (1984) Serotoninergic axonal contacts on identified cat spinal dorsal horn neurons and their corrclation with nucleus raphe magnus stimulation. J. Comp. Neurol. 228: 129-141.

Nemeroff, C. B., A. J. Osbahr, III, P. J. Manberg, G. N. Ervin, and A. J. Prange, Jr. (1979) Alterations in nociception and body temperature after intracisternal administration of neurotensin, $\beta$-endorphin, other endogenous peptides, and morphine. Proc. Natl. Acad. Sci. USA 76: 5368-5371.

Oliver, C., R. L. Eskay, N. BenJohnathon, and J. C. Porter (1974) Distribution and concentration of TRH in the rat brain. Endocrinology 95: 540-546.

Osbahr, A. J., III, C. B. Nemeroff, D. Luttinger, G. A. Mason, and A. J. Prange, Jr. (1981) Neurotensin-induced antinociception in mice: Antagonism by thyrotropin-releasing hormone. J. Pharmacol. Exp. Ther. 217: 645-651.

Ruda, M. A., J. Cofficld, and N. W. M. Steinbusch (1982) Immunocytochemical analysis of serotonergic axons in laminae I and II of the lumbar spinal cord of the cat. J. Neurosci. 2: 1660-1671.

Seybold, V. S., and R. P. Elde (1982) Neurotensin immunoreactivity in the superficial laminae of the dorsal horn of the rat. I. Light microscopic studies of cell bodies and proximal dendrites. J. Comp. Neurol. 205: 89-100.

Sharif, N. A., and D. R. Burt (1983) Receptors for thyrotropin-releasing hormone (TRH) in rabbit spinal cord. Brain Res. 270: 259263.

Shioda, S., and Y. Nakai (1983) Immunocytochemical localization of TRH and autoradiographic determination of ${ }^{3} \mathrm{H}-\mathrm{TRH}$-binding sites in the arcuate nucleus-median eminence of the rat. Cell Tissue Res. 288: $475-487$.

Vale, W., and C. Rivier (1975) Hypothalamic hypophysiotropic hormones. In Handbook of Psychopharmacology, L. L. Iversen, S. D. Iversen, and S. H. Snyder, eds., pp. 195-238, Plenum, New York.

Watkins, L. R., S. N. Suberg, and C. L. Thurston (1984) Effects of intrathecal (IT) thyrotropin releasing hormone (TRH) and arginine vasopressin (VAS) on pain and analgesia. Soc. Neurosci. Abstr. 10: 105.

White, S. R. (1983) Effects of thyrotropin-releasing hormone on glutamate excitation of rat spinal motoneurons. Soc. Neurosci. Abstr. 9: 716.

Winokur, A., and R. D. Utiger (1974) Thyrotropin-releasing hormone: Regional distribution in rat brain. Science 185: 265-267. 